\title{
Estudo da expressão de galectina-3 em carcinomas de língua de camundongos
}

\section{Study of the galectin-3 expression in tongue carcinomas of mice}

Paulo Rogério de Faria'; Thaissa Lopes de Melo²; Roger Chammas ${ }^{3}$; Kelen Christine do Nascimento Souza'; Sérgio Vitorino Cardoso ${ }^{4}$; Adriano Mota Loyola ${ }^{4}$

\begin{abstract}
unitermos
Carcinoma epidermóide

Galectina-3

Língua

Camundongos

Imuno-histoquímica

\section{resumo}

Introdução: A galectina-3 (Gal-3) é uma lectina de mamíferos ligante de resíduos $\beta$-galactosídeos. Numerosos estudos têm mostrado que a Gal-3 apresenta importantes papéis na biologia tumoral, atuando em fenômenos como apoptose, metástase e transformação maligna. No entanto, em carcinomas de cabeça e pescoço, a real significância da sua expressão ainda é pouco compreendida. Objetivo: O objetivo deste estudo foi avaliar a expressão de Gal-3 em tumores de língua induzidos experimentalmente em camundongos desafiados com o carcinógeno 4-nitroquinolona-1-óxido (4NQO). Material e métodos: Quarenta e dois camundongos $\mathrm{C} 57 \mathrm{BL} / 6$, machos, foram desafiados com $4 \mathrm{NQO}$ na água de beber por 16 semanas e sacrificados em diferentes períodos depois do tratamento. Após o sacrifício, as línguas foram removidas, processadas, coradas por hematoxilina e eosina (HE) e microscopicamente analisadas quanto à presença de carcinoma. Ensaio imuno-histoquímico para detecção do antígeno Gal-3 e análise descritiva da sua expressão nos tumores induzidos foram realizados. Resultados: Ao final do experimento, foram produzidos 15 tumores. No tecido epitelial não-neoplásico, forte imunorreatividade foi observada apenas na camada parabasal. Nas camadas mais superficiais a intensidade de marcação foi mais fraca, e na camada basal variou de ausente a fraca. Todos os carcinomas bem diferenciados exibiram fraca marcação, exceto nas áreas queratinizantes. No único caso de carcinoma pouco diferenciado, forte imunorreatividade para Gal-3 foi observada. Conclusão: Nossos resultados descritivos mostram que a transformação maligna é acompanhada de redução da intensidade de expressão da Gal-3 e que o aumento da sua expressão com a perda da diferenciação neoplásica sugere a sua vinculação com agressividade tumoral.
\end{abstract}

\section{abstract}

Background: Galectin-3 (Gal-3) is a b-galactoside-binding mammalian lectin. Numerous studies have demonstrated that Gal-3 plays an important role in tumor biology, acting in some events such as apoptosis, metastasis and malignant transformation. However, in carcinomas of head and neck, the real significance of Gal-3 expression requires a better understanding. Objectives: The aim of this paper was to evaluate Gal-3 expression in tongue carcinomas experimentally induced in mice challenged with carcinogen 4-nitroquinoline1-oxide (4NQO). Material and method: Forty-two C57BL/6 male mice were challenged with 4NQO in drinking water for 16 weeks and killed at different periods after induction. In each period, their tongues were removed, routinely processed, stained with hematoxylin and eosin $(H \& E)$ and microscopically analyzed as to the presence of carcinoma. Immunohistochemical test for $\mathrm{Gal}-3$ and a descriptive analysis of its expression in induced tumors were performed. Results: By the end of the experiment, 15 tumors had been induced. In the non-neoplastic lingual epithelium, strong and weak immunoreactivity for Gal-3 was noted in parabasal and superficial layers, respectively. In the basal layer, Gal-3 expression varied from absent to weak. All the well-differentiated carcinomas showed weak immunoreactivity for Gal-3, except in keratinized areas. The only case of poorly differentiated squamous cell carcinoma indicated strong immunoreactivity for Gal-3. Conclusion: Our results show that malignant transformation is associated with reduced expression of Gal-3, whereas its increased expression in poorly differentiated carcinoma seems to be connected with tumor aggressiveness. key words

Squamous cell carcinoma

Galectin-3

Tongue

Mice

Immunohistochemistry

1. Doutor pela Universidade Federal do Triângulo Mineiro (UFMG)

2. Bacharela da Universidade Federal de Uberlândia (UFU).

3. Doutor pela Faculdade de Medicina da Universidade de São Paulo (FMUSP.

4. Doutor pela UFU.

Apoio financeiro: Conselho Nacional de Desenvolvimento Cientifico e Tecnológico (CNPq) e Fundação de Amparo à Pesquisa do Estado de Minas Cerais (FAPEMIG). 


\section{Introdução}

As galectinas pertencem a uma família de lectinas que mostram alta afinidade para resíduos $\beta$-galactosídeos ${ }^{(5)}$. Essas lectinas participam de diferentes fenômenos biológicos, como interação célula-célula e célula-matriz extracelular, diferenciação celular, angiogênese, apoptose e inflamação(7, 17).

Até o presente momento, 15 distintos membros têm sido descritos, dos quais a galectina-3 (Gal-3) é a mais amplamente estudada ${ }^{(12)}$. A Gal-3 (proteína de 29-31kDa) está expressa em uma grande variedade de tecidos e células ${ }^{(5,12)}$. Embora muito se conheça sobre seus aspectos estruturais e bioquímicos, pouco se sabe sobre as suas funções biológicas ${ }^{(11,16)}$. No entanto, dependendo da sua localização na célula, a Gal-3 pode exercer diferentes funções, algumas até mesmo antagônicas. Por exemplo, no núcleo, a Gal-3 tem sido implicada com splicing de RNA e proliferação celular, enquanto no citoplasma atua como molécula antiapoptótica. Além disso, no meio extracelular, age modulando positivamente a adesão celular e a apoptose $\mathrm{e}^{(7,17)}$.

Recentemente, vários estudos têm demonstrado a expressão de Gal-3 em diferentes tumores, bem como a sua associação com progressão tumoral e metástases em diferentes linhagens celulares tumorais $(9,13,14,20)$. Contudo, para tumores humanos derivados de células epiteliais, incluindo os de cabeça e pescoço, os resultados são ainda contraditórios. Por exemplo, em carcinomas epidermóides de esôfago, laringe e língua parece não existir associação entre expressão de Gal-3 e metástases locorregional ou à distância ${ }^{(9,14)}$. Por outro lado, em tumores de glândulas salivares essa associação parece ser positiva ${ }^{(20)}$. Em carcinoma colorretal, aumento ou diminuição da expressão de Gal-3 têm sido associados à progressão para um estado metastático ${ }^{(16)}$.

Como a literatura ainda mostra resultados contraditórios em relação à expressão de Gal-3 em carcinomas de cabeça e pescoço, propusemo-nos, no presente trabalho, a estudar a sua expressão em carcinomas epidermóides induzidos experimentalmente em língua de camundongos desafiados com o carcinógeno 4-nitroquinolona-1-óxido (4NQO). Nossos resultados mostraram uma diminuição da expressão de Gal-3 nos carcinomas epidermóides bem diferenciados, exceto nas áreas de diferenciação escamosa evidente, em que a expressão foi mais intensa. Todavia, no único caso de carcinoma epidermóide pouco diferenciado, a expressão de Gal-3 foi predominantemente forte, mas sem exibir padrão de distribuição aparente. Essa lesão foi mais invasiva que aquelas bem diferenciadas. Nossos resultados descritivos mostram que a transformação maligna é acompanhada de redução na intensidade de expressão da Gal-3. Além disso, sua expressão aumentou com a perda de diferenciação neoplásica, sugerindo que ela poderia estar associada à agressividade tumoral. Uma pertinente discussão sobre os nossos achados na luz dos atuais conhecimentos sobre essa importante molécula foi também realizada.

\section{Material e métodos}

\section{Animal}

Quarenta e dois camundongos $\mathrm{C} 57 \mathrm{BI} / 6$, machos, de 6 semanas de idade, pesando entre 21 e $23 \mathrm{~g}$, foram usados nesse estudo. Eles foram aleatoriamente divididos em cinco subgrupos (contendo oito a dez animais cada), correspondentes aos cinco períodos de observação escolhidos para monitoramento do desenvolvimento dos tumores: semana 16 (oito animais), semana 20 (oito animais), semana 24 (oito animais), semana 28 (10 animais) e semana 32 (oito animais). Durante todo o experimento os animais foram mantidos sob condições controladas de temperatura $\left(22^{\circ} \mathrm{C}\right)$ e ciclo claroescuro de 12 horas. Todo o experimento foi conduzido de acordo com o Guia de Experimentação Animal do Colégio Brasileiro de Experimentação Animal (COBEA).

\section{Protocolo de experimentação}

O tratamento com o $4 \mathrm{NQO}$ foi baseado no protocolo descrito por Tang et al. ${ }^{(19)}$, com algumas modificações. Resumidamente, o 4NQO (Sigma, EUA) foi diluído em água filtrada na concentração de $100 \mu \mathrm{g} / \mathrm{ml}$ e administrado por um período máximo de 16 semanas ininterruptas. Depois desse tempo, o tratamento foi interrompido e os animais passaram a beber apenas água filtrada até o sacrifício, o qual obedeceu aos seguintes tempos: semanas 16 (após o término de tratamento), 20, 24, 28 e 32. Durante todo o período de tratamento a solução de $4 \mathrm{NQO}$ foi sistematicamente mudada semanalmente.

\section{Dissecação e preparação histológica}

Sob sedação, os camundongos foram sacrificados por deslocamento cervical e submetidos à necropsia. As línguas foram dissecadas e imediatamente fixadas em solução formalina tamponada a $10 \%$ por 24 horas. Posteriormente, as línguas foram seccionadas em três fragmentos (anterior, médio e posterior), rotineiramente processados e embebi- 
dos em parafina. Fragmentos teciduais de $5 \mu \mathrm{m}$ de espessura foram obtidos e corados com hematoxilina e eosina (HE) para detecção dos carcinomas epidermóides. Além disso, secções teciduais de $3 \mu \mathrm{m}$ de espessura foram obtidas para ensaio imuno-histoquímico objetivando investigação da expressão do antígeno Gal-3.

\section{Exame anatomopatológico}

Todos os fragmentos teciduais foram analisados microscopicamente visando identificar o desenvolvimento de carcinomas epidermóides e classificá-los de acordo com os atuais critérios histopatológicos estabelecidos pela Organização Mundial da Saúde (OMS) $)^{(1)}$.

\section{Ensaio imuno-histoquímico}

Ensaios imuno-histoquímicos para detecção do antígeno Gal-3 foram realizados em cortes histológicos de 3 $\mu \mathrm{m}$ de espessura em lâminas previamente tratadas com organosilano, seguindo-se a técnica da estreptoavidinabiotina-peroxidase (SABP) padrão. Após desparafinização e reidratação dos cortes, realizou-se a recuperação antigênica em tampão citrato $(10 \mathrm{mM}, \mathrm{pH}$ 6) em panela de pressão por 4 minutos. Depois do bloqueio da atividade endógena da peroxidase (solução aquosa de $\mathrm{H}_{2} \mathrm{O}_{2}$ a $10 \mathrm{~V}$ por 15 min) e de ligações inespecíficas (solução composta de leite desnatado a $1 \%$, Triton-X a 0,05\% em tampão PBS) por 20 min à temperatura ambiente, incubou-se o anticorpo primário anti-Gal-3 (hibridoma feito em rato gentilmente cedido pelo Dr. Roger Chammas, do Laboratório de Oncologia Experimental da Universidade de São Paulo [USP]), na diluição de $1: 30$, overnight, a $4^{\circ} \mathrm{C}$, em câmara úmida. Após lavagem em solução tampão salina de fosfato (PBS), os cortes foram incubados com anticorpo secundário antirato biotinilado (Vector, EUA) na diluição de 1:500 por 30 min a $37^{\circ} \mathrm{C}$. A reação foi revelada com diaminobenzidina (Sigma, EUA) e os cortes, contracorados com hematoxilina de Harris. Para controle negativo das reações, os anticorpos primários foram substituídos pela solução diluente contendo albumina sérica bovina (BSA) a 1\% e azida sódica a 0,1\% diluídas em tampão PBA. Amostra de carcinoma papilar de tireóide positiva para Gal-3 foi usada como controle positivo da reação.

Para avaliação comparativa da imunomarcação de Gal-3 nos carcinomas epidermóides e no tecido epitelial não-neoplásico nos diferentes períodos de observação considerou-se a intensidade de marcação da seguinte forma: negativo (-), fraco (+), moderado (++) e forte (+++) nas diferentes áreas dos tumores, como região intratumor, áreas adjacentes às pérolas córneas e mais infiltrativas e diferentes camadas do tecido epitelial não-neoplásico.

\section{Resultados}

Dos 42 camundongos que iniciaram o experimento, cinco deles morreram, sendo dois na semana 20 e três na 32, perfazendo um total de 37 animais ao final do experimento.

\section{Análise microscópica dos carcinomas de língua}

Ao final do experimento, 15 animais foram acometidos por carcinoma epidermóide em língua, concluindo com um total de 15 tumores. O número de animais acometidos aumentou com o passar do tempo, sendo um animal na semana $16(12,5 \%)$, dois na $20(33,3 \%)$, um na $24(12,5 \%)$, seis na $28(60 \%)$ e cinco na semana $32(100 \%)$. Apenas um tumor foi classificado como pouco diferenciado, sendo observado num camundongo da semana 20 . Os outros 14 tumores foram classificados como bem diferenciados.

\section{Análise imuno-histoquímica de Gal-3}

Um resumo da intensidade de marcação para Gal-3 nos carcinomas epidermóides e no tecido epitelial não-neoplásico pode ser visto na Tabela.

Intensidade de marcação para Gal-3 nos carcinomas epidermóides e no tecido

Tabela epitelial não-neoplásico

\begin{tabular}{ll}
\hline Localização & Intensidade de marcação* \\
Carcinomas & \\
Bem diferenciados & + \\
Intratumor & + \\
Infiltrativa & - \\
Pérolas córneas & +++ \\
Pouco diferenciado & +++ \\
Intratumor & +++ \\
Infiltrativa & +++ \\
Epitélio não-neoplásico & \\
Basal & - \\
Parabasal & +++ \\
Intermediário & +++ \\
Granuloso & - \\
Queratinizado & - \\
\hline
\end{tabular}

*Predomínio de marcação nas diferentes regiões.

(-): negativo; (+): fraco; (++): moderado; (+++): forte. 
A imunomarcação para Gal-3 mostrou distribuição topográfica constante no epitélio não-neoplásico, com células da camada basal exibindo imunorreatividade fraca ou ausente, com predomínio desta. Quando presente, a marcação foi principalmente citoplasmática. Contudo, células mostrando marcação tanto citoplasmática quanto nuclear foram observadas focalmente. Forte imunorreatividade nuclear e citoplasmática para Gal-3 foi observada nas camadas parabasal e intermediária. Nas camadas mais superficiais, a intensidade de marcação foi variada, com algumas células demonstrando forte marcação nuclear e moderada a fraca em citoplasma. Além disso, células negativas tanto em núcleo quanto em citoplasma também foram observadas (Figura 1A). No geral, a imunomarcação tumoral foi mais fraca do que a observada no epitélio não-neoplásico, apresentando distribuição difusa, em padrão heterogêneo. Esse aspecto pôde ser visto mesmo em lesões com infiltração menos profunda (Figura 1B). Por outro lado, células neoplásicas localizadas próximas às regiões queratinizadas (pérolas córneas) exibiam imunomarcação mais intensa em comparação com as periféricas (Figura 1C). No único caso de carcinoma epidermóide pouco diferenciado observado em nosso estudo, a expressão de Gal-3 também foi em padrão heterogêneo, predominantemente difuso e de forte intensidade (Figura 1D). Além disso, essa forte expressão

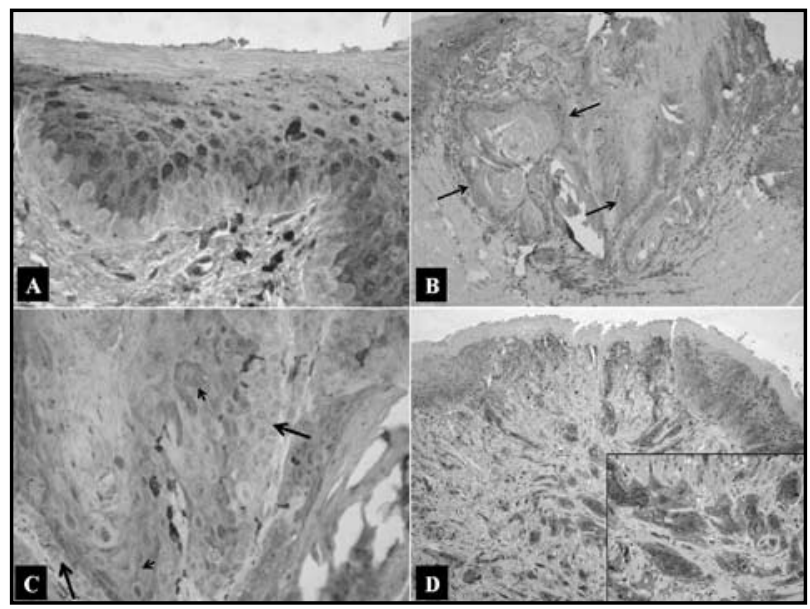

Figura 1 - Fotomicroscopia mostrando a imunorreatividade para Gal-3 na língua dos camundongos. A: tecido epitelial não-neoplásico com células exibindo forte marcação nuclear e citoplasmática em camadas parabasal e intermediária. Na camada superficial, notam-se células com forte marcação nuclear e moderada a fraca imunorreatividade citoplasmática, bem como células negativas tanto em núcleo quanto em citoplasma. Observar células da camada basal negativas para Gal-3 (aumento original de 400X) $B$ : carcinoma epidermóide bem diferenciado mostrando fraca imunorreatividade para Gal-3 em comparação com o tecido epitelial não-neoplásico adjacente. Note que a intensidade de marcação forte no tumor está situada nas regiões próximas às áreas de queratinização (setas) (aumento original de 100X); C: células neoplásicas adjacentes às pérolas córneas do mesmo carcinoma bem diferenciado da figura anterior exibindo forte imunorreatividade para Gal-3 (setas curtas). Note a baixa expressão de Gal-3 das células situadas mais perifericamente (setas longas) (aumento original de 400X); D: células neoplásicas do carcinoma epidermóide pouco diferenciado exibindo forte imunorreatividade para Gal-3 (aumento original de 100X, insert 400X) foi observada também nas áreas mais infiltrativas do tumor, fato não observado nos tumores bem diferenciados. Em todos os casos analisados, a imunorreatividade foi tanto nuclear quanto citoplasmática, sem, contudo, se perceber um padrão de distribuição predominante.

\section{Discussão}

O objetivo deste estudo foi analisar a expressão imunohistoquímica de Gal-3 em carcinomas epidermóides de língua induzidos experimentalmente em camundongos desafiados pelo 4NQO e discutir sua potencial relação com a transformação maligna e a progressão tumoral. Nossos achados evidenciaram que a intensidade de marcação de Gal-3 nos tumores foi mais fraca do que a observada no tecido epitelial não-neoplásico. Nos tumores bem diferenciados, essa marcação foi de intensidade mais forte nas áreas de pérolas córneas. Ademais, no único exemplar de carcinoma epidermóide pouco diferenciado, a marcação foi de forte intensidade, com distribuição difusa, em padrão heterogêneo. Esses resultados sugerem que transformação maligna do epitélio lingual pode estar associada à redução da expressão de Gal-3. Não obstante, a diferenciação tumoral parece estar vinculada à expressão de Gal-3. Por outro lado, na progressão tumoral, sua reexpressão parece indicar também aquisição do fenótipo menos diferenciado e mais infiltrativo. Esses resultados experimentais para as lesões bucais são similares aos relatados para os cânceres de cabeça e pescoço, cervical, ovariano, de mama e cólon em humanos, reforçando a idéia de que a redução de Gal-3 pode estar associada à aquisição do fenótipo transformado $(1,3,4,6,7)$.

Recentes estudos têm mostrado que a expressão de Gal-3 é dependente do grau de diferenciação celular ${ }^{(2,7)}$. Em tecido epitelial normal de mucosas bucal e vulvar, por exemplo, a Gal-3 está expressa principalmente nas camadas suprabasal e superficial( ${ }^{(3,9)}$. De forma similar, em áreas bem diferenciadas de tumores epiteliais, particularmente nas proximidades das pérolas córneas, a sua expressão também está aumentada em relação às células situadas mais perifericamente a essas áreas ${ }^{(2,3)}$. Corroborando esse dado, um estudo realizado recentemente em tumores de glândulas salivares mostrou que a Gal-3 foi detectada nas células luminais de estruturas semelhantes a ductos de carcinoma adenóide cístico, as quais são conhecidamente positivas para citoqueratinas 7, 8, 14 e 19(8). Em nosso estudo, observamos freqüentemente forte imunorreatividade para Gal-3 nas células situadas nas proximidades das pérolas 
córneas. Contudo, células situadas mais perifericamente a essas áreas ou distantes dessas regiões exibiam, no geral, fraca expressão de Gal-3, reforçando a hipótese de que essa lectina participa do processo de diferenciação celular.

Achado intrigante em nosso estudo foi o fato de o único caso de carcinoma epidermóide pouco diferenciado ter exibido expressão forte e difusa de Gal-3, inclusive nas áreas mais infiltrativas, aspecto não observado nos casos de carcinomas epidermóides bem diferenciados. No único estudo que analisou a expressão de Gal-3 em amostras de carcinoma epidermóide de língua por imuno-histoquímica, uma forte expressão nos tumores pouco diferenciados foi encontrada ${ }^{(9)}$. Achados similares têm sido relatados também na carcinogênese mamária humana, na qual foi identificada reexpressão de Gal-3 com progressão de lesões pré-cancerosas incipientes a carcinomas altamente invasivos $(3,16)$.

No que diz respeito à expressão forte de Gal-3 também nas áreas infiltrativas, alguns trabalhos têm encontrado resultados similares aos nossos ${ }^{(15)}$. No estudo de Sanjuán et al. ${ }^{(15)}$, foi observada forte expressão de Gal-3 em células situadas em áreas mais infiltrantes e indiferenciadas na maioria das amostras de câncer colorretal analisada. Além disso, em carcinomas de células escamosas de vulva grau 2 (presença de componente indiferenciado), forte expressão de Gal-3 foi encontrada nessas regiões indiferenciadas, sugerindo maior potencial invasivo para essas células tumorais imaturas ${ }^{(3)}$. Esses dados, em conjunto com os nossos, permitem sugerir que a forte expressão de Gal-3 deve traduzir um fenótipo menos diferenciado e também um comportamento tumoral mais infiltrativo, provavelmente favorecido por maior interação da Gal-3 com componentes estromais, como integrinas e glicoconjugados solúveis ${ }^{(10,18)}$.

\section{Conclusão}

Nossos achados apontam que a transformação maligna em tecido epitelial lingual de camundongos é acompanhada de redução da expressão da Gal-3. É muito provável que sua expressão esteja relacionada com diferenciação celular, tendo em vista que sua expressão foi predominantemente associada às áreas de maior diferenciação. Além disso, o aumento de intensidade de sua expressão em tumores menos diferenciados sugere que sua expressão nessas lesões esteja vinculada a um fenótipo mais infiltrativo, portanto mais agressivo.

\section{Referências}

1. BARNES, L. et al. Word Health Organization Classification of Tumours. Pathology and genetics of head and neck tumors. Lyon: IARC Press., 2005.

2. BETKA, J. et al. Galectin-3, and endogenous lectin, as a tool for monitoring cell differentiation in head and neck carcinomas with implications for lectin-glycan functionality. Acta Otolaryngol, v. 123, n. 2, p. 261-3, 2003.

3. BRUSTMANN, H. Galectin-3 and CDla-positive dendritic cells are involved in the development of an invasive phenotype in vulvar squamous lesions. Int J Gynecol Pathol, v. 25, n. 1, p. 30-7, 2006.

4. CASTRONOVO, V.; LIU, F. T.; VAN DEN BRULE, F. A. Decreased expression of galectin-3 in basal cell carcinoma of the skin. Int J Oncol, v. 15, n. 1, p. 6770, 1999.

5. CVEJIC, D. et al. Galectin-3 and proliferating cell nuclear antigen (PCNA) expression in papillary thyroid carcinoma. Exp Oncol, v. 27, n. 3, p. 210-4, 2005.

6. DELORGE, S. et al. Correlation of galectin-3/galectin-3binding sites with low differentiation status in head and neck squamous cell carcinomas. Otolaryngol Head Neck Surg, v. 122, n. 6, p. 834-41, 2000.

7. DUMIC, J.; DABELIC, S.; FLOGEL, M. Galectin-3: An openended story. Biochim Biophys Acta, v. 1760, n. 4, p. 616-35, 2006
8. FERRAZZO, K. L. et al. Galectin-3 immunoprofile in adenoid cystic carcinoma and polymorphous low-grade adenocarcinoma f salivary glands. Oral Oncol, n. 43, v. 6, p. 580-5, 2007.

9. HONJO, Y. et al. Expression of cytoplasmic galectin-3 as a prognostic marker in tongue carcinoma. Clin Cancer Res, v. 6, n. 2, p. 4635-40, 2000.

10. INOHARA, H. et al. Interactions between Galectin-3 and Mac-2-binding protein mediate cell-cell adhesion. Cancer Res, v. 56, n. 19, p. 4530-4, 1996.

11. LEE, J. W. et al. Decreased galectin-3 expression during the progression of cervical neoplásica. J Cancer Res Clin Oncol, v. 132, n. 4, p. 241-7, 2006.

12. LIU, F. T.; RABINOVICH, G. A. Galectins as modulators of tumour progression. Nat Rev Cancer, v. 5, n. 5, p. 29-41, 2005.

13. PIANTELLI, M. et al. Lack of expression of galectin-3 is associated with a poor outcome in node-negative patients with laryngeal squamous-cell carcinoma. J Clin Oncol, v. 20, n. 18, p. 3850-56, 2002

14. PLZÁK, J. et al. Galectin-3 -an emerging prognostic indicator in advanced head and neck carcinoma. Eur J Cancer, v. 40, n. 15, p. 2324-30, 2004.

15. SANJUÁN, X. et al. Differential expression of galectin 3 and galectin 1 in colorectal cancer progression. Gastroenterology, v. 113, n. 6, p. 1906-15, 1997. 
16. SHEKHAR, M. P. V. et al. Alterations in galectin-3 expression and distribution correlate with breast cancer progression. Am J Pathol, v. 165, n. 6, p. 1931-41, 2004.

17. SMETANA JR., K. et al. Nuclear presence of adhesion/growth-regulatory galectins in normal/malignant cells of squamous epithelial origin. Histochem Cell Biol, v. 125, n. 1-2, p. 171-82, 2006.

18. TAKENAKA, Y. et al. Malignant transformation of thyroid follicular cells by Gal3. Cancer Lett, v. 195, n. 1, p. 111-9, 2003.

19. TANG, X. H. et al. Oral cavity and esophageal carcinogenesis modeled in carcinogen-treated mice. Clin Cancer Res, v. 10, n. 1, p. 301-13, 2004.

20. TEYMOORTASH, A. et al. Expression of galectin-3 in adenoid cystic carcinoma of the head and neck and its relationship with distant metastasis. J Cancer Res Clin Oncol, v. 132, n. 1, p. 51-6, 2006.

\section{Endereço para correspondência}

Adriano Mota Loyola

Universidade Federal de Uberlândia - Campus Umuarama

Av. Pará, 1.720, Hospital de Clínicas, Laboratório de

Anatomia Patológica

CEP: 38405-900 - Uberlândia-MC

Tel.: (34) 3218-2703

Fax: (34) 3218-2626

e-mail: adrianol@hc.ufu.br 